\title{
The Impact of Personal and Cultural Factors on Green Buying Intentions with Mediating Roles of Environmental Attitude and Eco-Labels as Well as Gender as a Moderator
}

\author{
Amna Hasnain * $\quad$ Syed Hassan Raza ${ }^{\dagger} \quad$ Usama Shahzad Qureshi ${ }^{\ddagger}$
}

\begin{abstract}
The purpose of this paper is to examine the impact of personality traits of consumers regarding their green buying intention by measuring the mediation effects of eco-labels and environmental attitude along with the moderation of gender. To the researchers' best knowledge, there is a lack of research in developing countries in explaining influence of rarely researched factor such as loyalty proneness on green buying intention. To uncover this gap, using survey method data from a sample of 434 has been collected through a structured questionnaire distributed among employees of the different national and multinational companies. Findings suggest that consumer personality traits except collectivism have a significant impact on Green buying intention. Furthermore, mediation of ecolabels and environmental attitude along with moderation of gender has a strong impact on consumer's green buying intention. These findings depicted that green market is evolving in developing countries, so it has created an open avenue for marketers to better grab the opportunities from green products and focus on establishing that new category of green products in Pakistan. Moreover, present study helps to eliminate the research gap by evaluating the interaction effect of gender with environmental attitude and eco-labels on green buying intention.
\end{abstract}

Keywords: Green buying intention, consumer personality traits, eco-labels, environmental attitude, structural equation modeling

\section{Introduction}

The present state of economic development has been accompanied with augmented consumption of materials and energy, which has led to increasing greenhouse gas emiss- ions (Arto \& Dietzenbacher, 2014; Franzen \& Mader, 2016). Increased global population, advancements in technology, increased economic development, and non-sustainable consumption has resulted in negative impacts on the environment like environmental degradation. Drastic changes in the air, climate and water pollution, depletion of ozone layer, deforestation, acid rain and damages to fauna and flora are among the major disastrous events

\footnotetext{
* Lecturer. Institute of Management Sciences, Bahauddin Zakariya University, Multan, Pakistan.

E-mail: amna.hasnain@bzu.edu.pk

$\dagger^{\dagger}$ Corresponding Author: Lecture, Department of Communication Studies Bahauddin Zakariya University, Multan, Pakistan and PhD in Communication from UUM, Malaysia. E-mail: sherazibzu@gmail.com

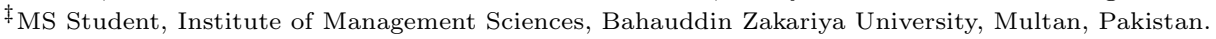


of the environment. Hence, sustainable patterns of consumption are inevitable (Chen \& Chai, 2010).

According to media these days environmental problems have been appearing as the mainstream issues for green marketing research. New insights will be brought forwarded by grasping and investigating the cultural influence of man-nature orientation values to confirm its effect on the intention of consumers to go for the purchase of green products. For instance (Chekima, Wafa, Igau, Chekima, \& Sondoh Jr, 2016) noted that understanding the cultural values will help to understand the motivation of individuals as well as it will explain many elements of the behavior of an individual and the social atmosphere across cultures and within cultures.

Also, past researchers claim that a large number of consumers are aware of the fact that their purchasing behavior has an impact on the environment and also causes many environmental problems (Lu, Chang, \& Chang, 2015; Sangroya \& Nayak, 2017; Tsay, 2009). This encourages profit-oriented firms to incorporate concepts of green consumerism into their marketing operations as well in their production operations because green consumption is now becoming a culture that represents a standardized set of behavior of happiness and comfort, satisfying the physical needs and adding up to the image of individual (Lu et al., 2015).

Cai, Xie, and Aguilar (2017) stated that there can be different reasons for consumers to go for green products, comprising of self-oriented and environmental motivations. For example, green products are more probable to be purchased by consumers having an ecological conscious profile. This showing personal health to be the most important self-oriented motivation regarding preferences for green products. The main objective of this study is to find the aspects that motivate the intention of consumers to purchase the green products based on the theory of planned behavior by Ajzen (1985). The focus of this study is on consumers purchase intention rather than behavioral for intention has broader implications and often will draw a positive effect on consumers behavior which is the actual purchase (Chekima et al., 2016). Thus to enhance the understandability of consumer green buying intention research scholars are required to incorporate the relevant mechanisms in terms of mediating effects.

Although in the developed countries ecological concerns are considered as a vital factor for their political, social and economic aspects of life nonetheless in developing countries particularly like Pakistan there is a limited knowledge exists that how people view the environment (Ali, Khan, Ahmed, \& Shahzad, 2011). This consumer's view scarcity can be addressed with the help of eco-labels, environmental attitude, man-nature orientation (Chekima et al., 2016), loyalty proneness (Lu et al., 2015) and collectivism (Frank, Enkawa, \& Schvaneveldt, 2015).

According to INDC (Intended Nationally Determined Contributions) report; submitted by Pakistan to United Nations Climate Change Secretariat; Pakistan has shown an increase of $123 \%$ of gases that are affecting the environment. Pakistan emits almost 10 million tons of gases in a year. If this remained the case then it will increase to $300 \%$ making an emission of 1603 million tons of gases. At this particular moment, Pakistan emits $0.8 \%$ of the worldwide gases emission and is ranked 135 in gas emitting countries. Hence, addressing this current scenario during United Nations Framework Convention on Climate 
Change (UNFCC) Pakistan aimed to reduce 20\% of gases emission till year 2030 and has also asked for support from developed countries as Pakistan is ranked no. 6 in list of countries that are adversely affected by negative impacts of climate changes.

Therefore, examination of the green buying intention of the Pakistani consumers is inevitable in the field of the green marketing research. By understanding and identifying the relevant influencing factors of Pakistani consumer's green buying intention would bridge up this gap. Further, within the perspective of relationship marketing, relationship outcomes like commitment, consumer trust, loyalty, and satisfaction albeit has been widely examined however, loyalty proneness has been rarely examined. In this standard, this research explains the impact of personality and cultural factors on green purchase intention by applying constructs from Theory of Planned Behavior (TPB). In doing so, a conceptual model has been developed by linking cultural values from Hofstede (2001) to understand the role of collectivism (cultural factor) as the determinants of green purchase intention. To understand influence of cultural orientation and personal traits of the individuals on green purchase intention, man nature from the Kluchhohn's value orientation model (Kluckhohn \& Strodtbeck, 1961) along with loyalty Proneness has been added in the proposed model. However, we argue that influence of these cultural and personnel traits is not straight forward, instead cultural and individual orientations may intensify the environmental attitude which serve as a process variable (mediator) to determine green buying intention.

Given that contemporary consumers have become sensitive towards environmental considerations of marketers (Huang, Yang, \& Wang, 2014; Huang et al., 2014). Consumers expect that organizations may integrate social issues (i.e., environmental issues) in their marketing campaigns along with profit oriented marketing activities. This sensitivity of the consumer have influence the organizations marketing communication activities (Keller, 2016). Especially, organizations promotional strategies have been integrated with green marketing communication strategies such as ecolabelling . Ergo, with the perspective of marketing communication, ecolabelling has been linked in the proposed model which may serve as the imperative nonverbal and verbal communication cue to motivate the individuals to adopt green intention. This study also unfolds the interaction of the gender with ecolabels and environmental attitudes in order to determine the green purchase intention. This may have vital implications for marketers, particularly this research provides information for the designing marketing communication strategies whereby marketers may understand the unanswered question in context of Pakistan that how males and females can differently interact with the information provided in their message (eco-label) in taking purchase decisions. Further sections shed light on all above aspects in detail.

\section{Literature Review}

\section{Green Buying Intention}

The term "societal marketing" to cover all the aspects that are comprehended in "green marketing', 'ecological marketing', 'environmental marketing' or 'sustainable marketing'. All these aspects explain that how things are evolved in developing a new trend that helped in reducing harmful environmental effects that were evolved from new techniques of man- 
ufacturing and marketing. In short, Green buying Intention is defined as the intention of consumers who wants to buy products that are environmentally friendly and have a less adverse impact on the environment (Jaiswal, 2012). Green purchasing or environmentally sustainable decisions give a chance to diminish the negative impact of the environment by espousing products that are environmentally friendly. Plastic bags have been banned in many states of India due to environmental degradation and consumers are extra charged for the plastic bags in shopping malls (Prakash \& Pathak, 2017). Hence, green buying behavior ensures efficient utilization of natural resources, saves the environment at large and defines the behavior of an ethical consumer (Noordin \& Jusoff, 2010). As a result of global warming, consumers are showing increasing concern regarding environment which is consequently opening up new avenues for firms to utilize sustainable and green opportunities.

Previous studies on green consumerism showed that a positive attitude to green products triggers the green buying intention (Huang et al., 2014). Gadenne, Sharma, Kerr, and Smith (2011) claimed that consumers support for environmental protection is also a factor that triggers green buying intention. Bang, Ellinger, Hadjimarcou, and Traichal (2000) claimed that those consumers who show much concern about their surroundings and environment are eager to spend more for renewable energy. Hence, firms need to recognize that green products and their role can cause improvement in environment quality (Escalas \& Bettman, 2005). These green products create a positive predisposition in consumer's mind (Pickett-Baker \& Ozaki, 2008). Thus, green products are preferred by consumers over nongreen products and they are subjected to the green buying intention (Kumar, Scheer, \& Steenkamp, 1995). Kim (2011) studied the role of personal values, perceived customer effectiveness, collectivism and environmental attitudes to develop an understanding of green consumption patterns in Korea. Chan (2001) found out the determinants influencing green purchase behavior in the Chinese context. Junaedi (2006) studied consumer behavior concerning the environment that helped in measuring intention to purchase the green product. Chairy (2012) claimed that in order to find out the green consumer behavior, intention to purchase a green product is a reasonable determinant.

The theory that helps in understanding the green buying intention is the theory of planned behavior (TPB) (Ajzen, 1991). The theory suggests that subjective norms, attitude toward the behavior and perceived behavioral control collectively develop the behavior of any individual and behavioral intentions. It is the most applied model that helps in explaining and predicting the differences in behavior while making choices. Researchers have used theory of planned behavior previously (Yazdanpanah \& Forouzani, 2015; Ritter, Borchardt, Vaccaro, Pereira, \& Almeida, 2015; Kim, 2011) to predict and examine the green purchase behavior and (TPB) also helps to explain the intentions to purchase organic food, organic skin, clothing, hair care products, hygiene products, and other different green consumption products (Chekima et al., 2016). The current study also draws the conceptual framework from (TPB) for measuring the green buying intention by adding assumption related to the collectivism, loyalty proneness and man-nature orientation driven from the value orientation theory (Kluckhohn \& Strodtbeck, 1961). 


\section{Collectivism}

Hofstede (2001) properly defined culture as the mind's collective programming that differentiates participants of one group's individuals from the participants of other group individuals. Hofstede (1997) classified cultural dimensions that are comprised of individualism/collectivism, power distance, uncertainty avoidance, long-term orientation, and femininity. Lee (2008) explored different important dynamics that had shown a great influence on Hong Kong consumers regarding their green buying intention and among those collectivism was the important factor. Collectivism/Individualism are among strongest dimensions that define consumer behavior (Husted \& Allen, 2008). In Individualist culture or society there exists a strong "I" and the only factor that is valued is "self-actuali-zation" whereas in collectivist culture or societies there strongly exists a "We" factor. Decisions made by groups are preferred in order to develop the in-group or intragroup harmony (Laroche, Kalamas, \& Cleveland, 2005).

Noordin and Jusoff (2010) examined job satisfaction of individualists and collectivist and found out that Malaysian employees are collectivist and they have higher satisfaction regarding their pay, work, promotion, with their coworkers and supervisors than their counterpart individualists. The locus of control in intergroup behavior is on social identity rather than personal identity so intergroup behavior is distinguished from interpersonal behavior (Saad, Cleveland, \& Ho, 2015). Kanchanapibul, Lacka, Wang, and Chan (2014) stated that collectivism influence different and various social behaviors as collectivists are more inclined to recycling behavior than their individual counterparts.

Lee (2008) explored that collectivism was the important factor among all dynamics in influencing green buying intention of Hong Kong consumers. Prior Researchers have also stated that within services perspective there exists a strong relationship between behavioral intentions and collectivism/individualism (Frost, Goode, \& Hart, 2010). Collectivism and Individualism are the most prominent dimension of an individual to determine its purchase intention (Triandis \& Gelfand, 1998). In the light of aforementioned literature, it is hypothesized that:

\section{$H_{1}$ : Collectivism has a positive impact on green buying intention.}

A collectivist being self-opened person gets his green behavior influenced by more cognitive and attitudinal concepts. Collectivists have group aims to pursue them to energetically resolve issues regarding environment by having more grounded convictions that their conduct has any sort of effect in plummeting the ecological issues (Kim \& Choi, 2005). Responsibility for environmental purchase will be more prominent in consumers with collectivist quality being more grounded in them. In line with this awareness of the environmental issue has been revealed more by collectivist culture as compared to individualistic culture as in later context individuals are self centred and have less concern for environmental awareness (Arisal \& Atalar, 2016). So, it is hypothesized that:

$\mathrm{H}_{2}$ : Collectivism has a positive impact on environmental attitude.

In order to deliver credibility and reliability eco-labels play a vital role in shaping the consumer's intentions to purchase green products (Minoli, Goode, \& Smith, 2015). 
Cai et al. (2017) reported that trust on eco-labels of Taiwanese consumers significantly affected their predilections towards electronic goods. Due to purchases of product that is eco-labeled consumers are somehow getting conscious that how they can contribute to the good and healthy environment (Brécard, 2014). This information on labels helps to convince consumers who are sensitive towards sustainable patterns of consumption. Such consumers are willing to pay a premium price and they show a positive response towards the purchase of green products. Such ecological concern is high in collectivist societies.

$\mathrm{H}_{3}$ : Collectivism has a positive impact on eco-labels.

\section{Loyalty Proneness}

According to attitudinal perspective, loyalty is characterized as a utility of psychological process and it evaluates the loyalty as a function of a consumer's bond of affiliation to a particular brand or store. Loyalty marketing theories describe that an increase in the base of loyal consumers can increase the profitability significantly (Yoo \& Bai, 2013). Loyalty proneness is defined as the propensity of the individual consumer to actively participate or engage in affiliation with vendor, store or a retailer. Those consumers who have increased loyalty propensity will exhibit a promising behavior and attitude to a specific store and will also show their commitment to that store that is much more important to build the loyalty of a customer to that store. Loyalty proneness particularly leashes to the affective commitment of a consumer. Hence the increase in effective commitment will eventually increase the desire to happily continue and build their relationship as to the constructive consequences towards partner (Kumar et al., 1995). Consumers who are highly affectively committed are always motivated to purchase from a specific store (Steenhaut \& Van Kenhove, 2005).

$H_{4}$ : Loyalty proneness has a positive impact on green buying intention.

Environmental values are one of the powerful predictors that define actions of consumers and has a positive influence on consumers' willingness to take part in activities that protect the environment (Oliver \& Rosen, 2010). Similarly, Gallagher and Muehlegger (2011) found that in the purchase of an environmentally friendly car, social preferences for environmental quality and energy security were a major determinant for consumers. The green purchase intention is significantly impacted by environmental consequences showed by Malaysian users of baby diapers exhibiting their loyalty for such store. Jang, Kim, and Lee (2015) stated that individuals feel engrossed in a place or an environment because of a desire to placate specific needs related to what they considered socially and personally preferable.

$H_{5}$ : Loyalty proneness has a positive impact on environmental attitude.

Jang et al. (2015) stated that information, attachments, and affiliations to a particular store enhance the loyalty of consumers to that particular green product store. Affiliations with that green product store, in turn, leads consumers to create closeness and associations to purchase from that green product store based on the communication and information such store disseminates. In the light of aforementioned literature, it is hypothesized that:

$H_{6}$ : Loyalty proneness has a positive impact on eco-labels. 


\section{Man-nature Orientation}

In the 1940s and 50s, Florence Kluckhohn and Fred Strodtbeck developed the dimension of Man-nature Orientation within Value Orientation Theory (Kluckhohn \& Strodtbeck, 1961). Churchill Jr (1979) defined man-nature orientation as all friendly behaviors of human beings to nature due to their affiliation and love for nature and their potency to save the natural habitat or environment. Man-nature orientation is actually the relationship between nature and humans (Chan, 2001). Man-nature orientation defines that how an individual subjugates, live in harmony with nature or conquers the nature and hence man nature orientation functions close to the affectiveness level motivate the norms in which all behaviors of an individual reside. Instead of prospects and theories proposing cultural values acting as an influence on behavior and intention, up to recent data, there are insufficient studies that empirically investigated the relationship between green purchase intention and man-nature orientation.

\section{$H_{7}$ : : Man-nature orientation has a positive impact on green buying intention.}

In the context of impulsive buying and clothing fashions, man-nature orientation is playing its vital positive role to facilitate the buying behavior (Rajagopal, 2011). Mannature orientation links up to individual's environmental attitudes probing them to pursue environmental responsive buying behavior (Chekima et al., 2016). Previous studies have overlooked the use of value orientations frameworks such as established by Kluckhohn and Strodtbeck (1961) and categorized in five value orientations. Man-nature orientation is related with one's tendency of living in harmony with nature as described by value orientation theory. This dimension was included by some past researchers such as Chan (2001) for explaining the green purchase behavior. In contrast however, we argue that consumers learn attitudes through their value orientation which trigger the mechanism processing in turn, influence the green intention. Up to best of our knowledge no study has been conducted in Pakistani context to find out this influence of man-nature orientation on environmental attitudes. Hence this cultural value shows the relationship that is grounded in the environment and man as well as it describes the behavior and attitude of man towards nature and natural environment.

$H_{8}$ : Man-nature orientation has a positive impact on environmental attitude.

Environmental consumerism is one of the types of environmentally conscious behavior that states the purchase and consumption of products that are nature-friendly. Household items manufactured with recyclable packaging, energy-efficient light bulbs, and biodegradable detergents are some of the examples of such products. Such products are purchased or consumed by the exposure to information by the marketer that includes information that is being provided on the product labels and media advertising. Such labels help consumers or act as a guide for them to choose nature-friendly products. Thus:

$H_{9}$ : Man-nature orientation has a positive impact on eco-labels. 


\section{Environmental Attitude}

Whenever an individual shows attitude, he/she is judging things on the basis of decisions made by emotions, that may be unpleasant or pleasant, bad or good, disastrous or helpful and dislikable or likable (Ajzen, 1991). Milfont and Duckitt (2010) defined Environmental attitude as the psychological predisposition that is been shown by examining the natural habitat or environment with some notches of disfavor and favor. The literature on pro-environmental attitudes connotes anthropocentric and ecocentric paradigms of the environment. In anthropocentric paradigm, human beings are positioned in the focal point of the model.

On the other hand, ethnocentric paradigm places natural habitat or environment in the focal point of the model (Husted, Russo, Meza, \& Tilleman, 2014). Past researchers show that individuals who show care for the natural habitat or environment are philanthropic and they put environmental values on an upper side of themselves (Crumpei, Boncu, \& Crumpei, 2014). Barbaro, Pickett, and Parkhill (2015) explored that all those individuals who exhibit a higher need for cognition will embrace sturdier attitudes towards the environment and hence they ratify further pro-environmental objectives. Pro-environmental buying behavior is being influenced by consumers environmental concerns. Environmental concerns of such consumers pose that how actively they are involved in ecological protection. Such consumers are prone to buy environment-friendly products exhibiting their commitment to the environment (Prakash \& Pathak, 2017).

$H_{10}$ : Environmental attitude has a positive impact on green buying intention.

Turkyilmaz, Uslu, and Durmus (2015) stated that collectivist people show grouporiented goals, low-level competition, interdependence, interpersonal harmony and social hierarchies. Past studies have identified that consumers have now become sensitive about the environment issues. This sensitivity have developed a sense of a collective concerns among the individuals that their purchase decisions may impact the environment. Such collective concerns of individuals related to the environmental issues may increase the favorable attitudes towards green products . Similarly, in line with cultural values' notion we argue that, theses collective concerns about the environmental issues may not always translate into green intention, instead these rely on the individuals developed environmental attitude in context of the cultural pattern. As a result, all those individuals who are collectivists and perceive it for collective benefits may preferably indulge themselves in an environmental friendly attitude (Kanchanapibul et al., 2014). As a collectivistic society its more likely that Pakistan's people may develop more favorable environmentally friendly attitude. Keeping all discussion in view along with the postulates of Hofstede's model for collective societies' concerns about the collective goal we hypothesize that:

$H_{11}$ : Environmental attitude mediates the relationship between collectivism and green buying intention.

Chekima et al. (2016) stated that environmental knowledge and environmental concerns do not exceed attitudes to the environment, by not only affecting the green products purchase intention rather also showing that it acts as an important factor in enhanc- 
ing an individual consumer's willingness to give more to purchase green products. Also, man-nature orientation is positively linked with environmental friendly purchase behavior. According to Kluckhohn and Strodtbeck (1961).

$H_{12}$ : Environmental attitude mediates the relationship between man-nature orientation and green buying intention

$H_{13}$ : Environmental attitude mediates the relationship between loyalty proneness and green buying intention.

\section{Eco-labels}

Clemenz (2010) stated that from last 20 years eco-labeling has become a widely used tool as different firms claim that they present a lucrative competitive communication strategy. Giridhar (1998) stated that eco-labels are the collective environmental performance of any product. Eco-labels thus act as an influencing factor for choosing the products (Proto, Malandrino, \& Supino, 2007). In order to deliver credibility and reliability eco-labels play a vital role in shaping the consumer's intentions to purchase green products. All the information used for promotion on eco-labels are obtained from resources like governing bodies, administrative bodies, media groups, trade associations, campaigning groups and manufacturer (Minoli et al., 2015). To identify the green products consumers often count on eco-labels.

\section{$H_{14}$ : Eco-label has a significant impact on green buying intention.}

Cai et al. (2017) stated that to label a green product there are three specific features: (a) at the end of its life cycle product is recyclable, (b) transportation and manufacturing doesn't have a negative impact on environment, and (c) during its production and supplychain labor workers are treated fairly. Eco-labels tell consumers about the impact of a product through its life cycle on the environment at sale point. Also, it tells about the credence attributes of the green products (Chekima et al., 2016). Almost 70 percent of the purchase decisions of consumers are impelled by messages shown about environmental friendly in advertising and labeling of the products, also 83 percent of the consumers said that they prefer buying products that are environmentally safe.

From the communication perspective, eco-labels can disseminate the information about the environmental friendly product attributes and thus serve as a communication cue. Literature suggests that communication cues can have psychological implications for the consumers (Raza, Bakar, \& Mohamad, 2018). For instance, promotional messages containing eco-friendly labels and signs serve as the non-verbal cues for the consumers (Belanche, Flavián, \& Pérez-Rueda, 2017). These non-verbal cues can lead towards the positive evaluation of the product in question through a cognitive process. The process of product evaluation involves the assessment of the product features. Theoretically this cognitive process is directly related with the interaction of prior information available to an individual with the communication cues given in promotional messages (Aman, Harun, \& Hussein, 2012; Keller, 2016). The prior information upholded by the individual relies on the learned behavioral pattern (usually culturally learned) as well as the consumer's bond with par- 
ticular product (Raza, Hasnain, \& Khan, 2018). Theses collective beliefs in a society like Pakistan along with the man-nature orientation can help to install positive cognition about the green products. From a consumer perspective, three elements can probe consumers to go for green consumption and these are knowledge of eco-labels, consumer perception of the company and accuracy of eco-labels. Thus from the above literature, it is deduced that:

$H_{15}$ : Eco-labels mediates the relationship between collectivism and green buying intention.

$H_{16}$ : Eco-labels mediates the relationship between loyalty proneness and green buying intention.

$H_{17}$ : Eco-labels mediates the relationship between man nature orientation and green buying intention.

\section{Demographics: Moderation of Gender}

Different studies have been conducted to examine the environmental behavior and variables in regard to gender differences. Previous research showed that females are the ones who are highly likely to participate in pro-environmental behavior. Also, showing greater intention to go for green products (Kalamas, Cleveland, \& Laroche, 2014; Matthes, Wonneberger, \& Schmuck, 2014). Chekima et al. (2016) stated there is a significant difference in environmental attitude and behaviors patterns among gender, showing women are more likely to exhibit environmental concern than men.

$H_{18}$ : Gender moderates the relationship between environmental attitude and green buying intention such that the relationship is more positive for females than males.

Scholars have found that knowledge about ecological issues is more in men then women and they show behavior accordingly (Diamantopoulos, Schlegelmilch, Sinkovics, \& Bohlen, 2003). Women were more likely to report information on labels of a specific product showing their concern for the environmentally friendly product . So, guided by the past literature gender differences results in different environmental behavior. Overall, the study proposes that environmental behavior is likely to be more positively related to eco-labels for women who perceive eco-labels positively than men and hypothesize:

$H_{19}$ : Gender moderates the relationship between eco-labels and green buying intention such that the relationship is more positive for females than males. 
Figure 1

Conceptual Framework

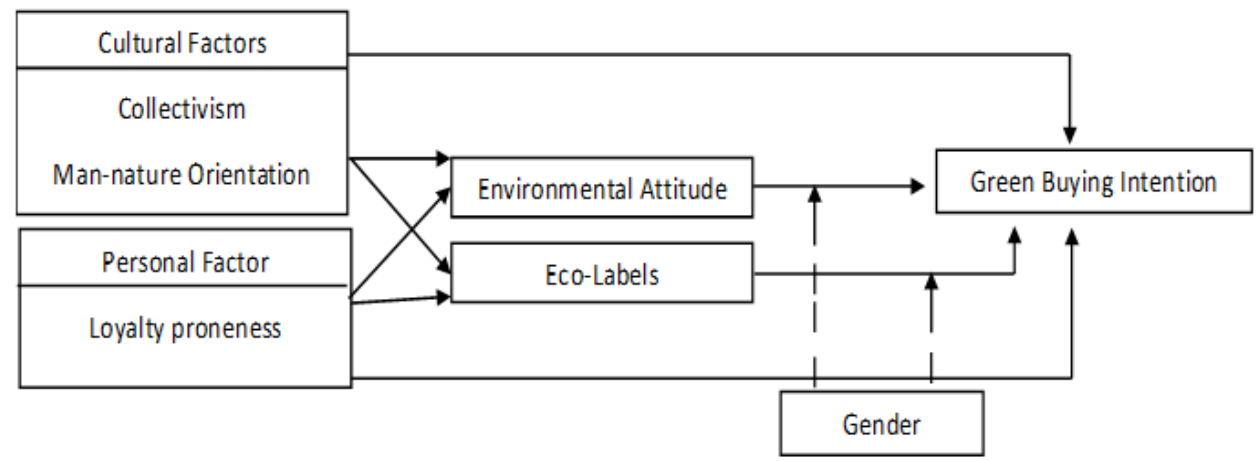

\section{Research Methodology}

\section{Sample and Procedures}

To validate the conceptual model a survey method has been employed. The data has been collected from the sample $(n=434)$ comprised of employees from different national and multinational companies JS Global, Mapple Leaf, Lucky Cement, Nestle, Pepsi Multan, Youngs Foods, Mahmood Group Multan, Indus Pharma, Hyperlink, and Virtual Base.

The rationale behind selecting such sample was based on belief that consumers with higher education will be well aware of the concept of green buying intention. Structured questions were developed and distributed among employees of companies by using the convenient sampling.

The sample size of 500 respondents represent the estimated population size $(\mathrm{N}=4000)$ of national and multinational companies operating in the Multan region. This sample size is steady with the VanVoorhis and Morgan (2007) size determination formula which indicates that the $(\mathrm{n}=434)$ is a representative sample for the population $(\mathrm{N}=4000)$.Furthermore, power analysis has been conducted on G-Power software to justify the sample size. The power analysis indicated appropriate effect size $\mathrm{f}=.35$ for a sample size of 434 with power $.80(\mathrm{p}=.05)$, since, the model has a maximum of 6 predictors (Three IV's; Two Mediators; and One Moderating Variable).

\section{Measurement}

This study involves seven constructs; three independent, two mediators, one moderator and one dependent variable. A structured questionnaire was adopted comprising of 37 items. In order to measure collectivism, a scale has been adopted from the study of Triandis and Gelfand (1998). It consists of seven items to measure this construct. This variable has been measured from the scale adopted from the study of Chekima et al. (2016) consisting of 
three items to measure this variable. This scale has previously been used by Chan (2001). For the measurement of loyalty proneness, scale consisting of three items was adopted (Lu et al., 2015). This scale has previously been used by Steenhaut and Van Kenhove (2005). Environmental attitude has been measured by adopting the scale consisting of nine items (Chekima et al., 2016). This scale has previously been used by Chen and Chai (2010); Tanner and Wölfing Kast (2003). The construct of eco-label has been measured through the scale consisting six items (Chekima et al., 2016). This scale has previously been used by Rashid (2009). The construct of green buying intention has been measured through (Lu et al., 2015) using five questions. This scale has previously been used by Kim and Choi (2005). Further, the demographic variables (i.e., age and education level) has been observed as the control variable whereas, gender has been added in the model as the moderating variable. The demographic profile of the data revealed that sample consists of 21 to 58 -years old employees and $59 \%$ described them as masters, $23 \%$ as bachelor degree holders, $2 \%$ as M.phill and $16 \%$ as others (diploma holders etc.).

\section{Statistical Analysis Techniques}

The AMOS 24.0 was used with twofold aims first to test the proposed measurement and structural model fitness. Second, structural equation modeling was used to test the proposed hypotheses. For validating model CFA was ran to test the reliability and validity of the used items. The covariance based $\mathrm{CVB}=\mathrm{SEM}$ has been employed because the proposed theoretical model is based on theory-driven assumptions while VB-SEM is useful in exploratory studies-when "theory is less developed" (Memon, Ting, Ramayah, Chuah, \& Cheah, 2017). To confirm such theoretical-assumptions, researchers (Hair Jr, Babin, \& Krey, 2017) thus have suggested that CVB-SEM is suitable for such theory-laden models. However, for evaluating the moderation effect of gender (categorical variable), regression analysis was used by following the recommendation of Dawson (2014) after computing the binary measures.

\section{Analysis and Findings}

Table 1 shows the Bivariate correlations between the constructs were significant. After removing the 10 percent outliers found in data, normality of data was attained for all six variables of the study.

Table 1

Descriptive and Pearson Correlation Statistics

\begin{tabular}{lllllllllll}
\hline & $\mathbf{M}$ & SD & SK & KR & CL & LP & MN & EA & EL & GI \\
\hline CL & 4.120 & 0.441 & -0.340 & -0.310 & 1.000 & & & & & \\
LP & 3.310 & 0.752 & -0.140 & -0.230 & $0.150^{*}$ & 1.000 & & & & \\
MN & 3.830 & 0.652 & -0.460 & 0.340 & $0.310^{*}$ & $0.060^{*}$ & 1.000 & & & \\
EA & 3.930 & 0.540 & -0.320 & -0.300 & $0.390^{*}$ & $0.250^{*}$ & $0.480^{*}$ & 1.000 & & \\
EL & 3.570 & 0.562 & 0.120 & -0.270 & $0.330^{*}$ & $0.170^{*}$ & $0.350^{*}$ & $0.430^{*}$ & 1.000 & \\
GI & 3.630 & 0.601 & -0.020 & -0.360 & $0.240^{*}$ & $0.290^{*}$ & $0.260^{*}$ & $0.490^{*}$ & $0.420^{*}$ & 1.000 \\
\hline
\end{tabular}

VIF was calculated to ensure the non-multicollinearity by running linear regression 
amongst all six variables linkages in the proposed models. The value of below 10 was revealed which concluded as there is no issue of multicollinearity was found. We ran structural equation models on AMOS 24.0 and used maximum likelihood estimate. This permits us to examine the mediating models with mediating variables of eco-labels and environmental attitude and their relations with the independent variables of this study collectivism, man nature, and loyalty proneness and with a green intention dependent variable. Direct and indirect paths were examined amongst the dependent variable of green intention.

Confirmatory factor analyses on all six constructs reveal that there is no multidimensionality exists (see Table 2). Confirmatory factor analysis outcomes reveal that ecolabeling, environmental attitude, green intention, collectivism, man nature and loyalty proneness were empirically distinct (see Table 2). Evidence-based on the above six fit indices used for the analyzing the model reveals a fit model structure (Hu \& Bentler, 1999) Moreover, to analyze the common method biases, separate confirmatory factor analyses by loading the all six constructs items on a unique factor also reveals model fit based on six directories of fitness presented in Table 2. If the measurement model fits there is no evidence of bias found, therefore, recommended proceeding analysis.

Table 2

Confirmatory Factor Analysis

\begin{tabular}{lccccccc}
\hline Model & $\mathbf{x} 2$ & df & $\mathbf{x 2} /$ df & GFI & IFI & CFI & RMSEA \\
\hline Original-factor & 497.93 & 292 & 1.740 & 0.920 & 0.910 & 0.910 & 0.040 \\
Common-factor & 392.97 & 265 & 1.480 & 0.940 & 0.950 & 0.950 & 0.033 \\
\hline
\end{tabular}

Meanwhile, measurement model also showed the convergent and discriminant validity (see Table 3), of all six variables, which are acceptable to advance with hypothesis testing.

Table 3

Discriminant and Convergent Validity

\begin{tabular}{lccccccccc}
\hline \multicolumn{1}{c}{$\alpha$} & CR & AVE & CL & LP & MN & EA & EL & GI \\
\hline CL & 0.690 & 0.820 & 0.512 & -0.716 & & & & & \\
LP & 0.750 & 0.750 & 0.505 & $.280^{*}$ & -0.711 & & & & \\
MN & 0.870 & 0.770 & 0.536 & $.470^{*}$ & $.030^{*}$ & -0.732 & & & \\
EA & 0.720 & 0.900 & 0.546 & $.560^{*}$ & $.270^{* *}$ & $.520^{*}$ & -0.739 & & \\
EL & 0.680 & 0.850 & 0.537 & $.410^{*}$ & $.340^{*}$ & $.520^{*}$ & $.640^{*}$ & -0.732 & \\
GI & 0.810 & 0.800 & 0.586 & $.450^{*}$ & $.370^{*}$ & $.510^{*}$ & $.420^{*}$ & $.620^{* *}$ & -0.766 \\
\hline *p < 0.05 ** $<0.001$, Values in parentheses represents square root of AVE= \\
Average Variance Extracted, CL = Collectivism, LP =Loyalty Proneness, MN= \\
Man Nature, EA = Environmental attitude, GI = Green Intention, \& CR = \\
Composite Reliability.
\end{tabular}

Additionally, all items of six constructs when loaded on their original factors it reveals significant results and remains within the limit of item deletion to attain the model fit, in total six items out 33-items were deleted, the findings accessible in Table 4. 


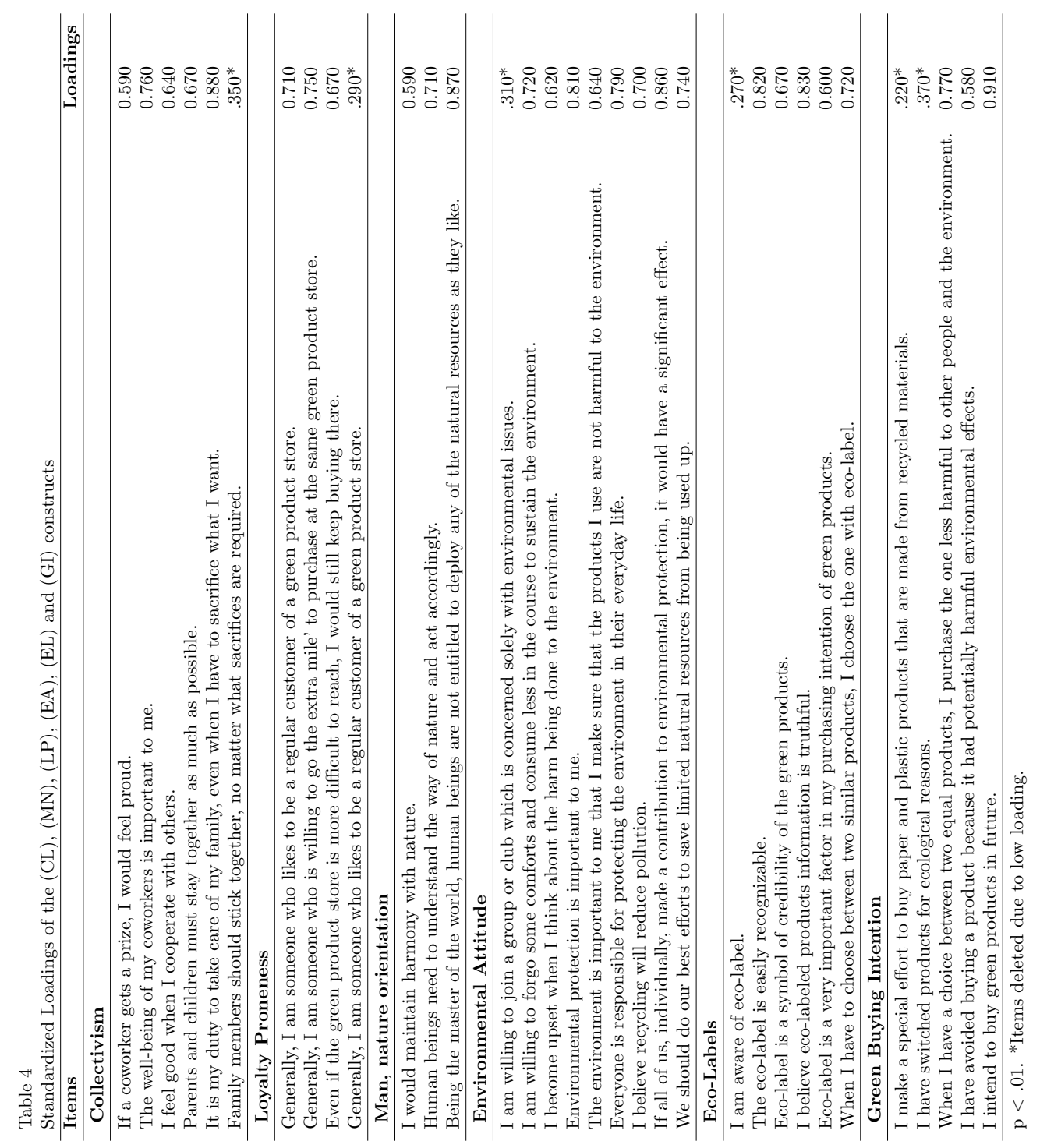




\section{Hypothesis Testing}

We first examined the proposed structural model fit with green intention as the outcome variable. Our model fits as it is within the range of fit indices presented in Table 5.

Table 5

Fit Indices for Predicting Green Buying Intention Structural Model

\begin{tabular}{lcccccccc}
\hline Model & $\mathbf{x} 2$ & $\mathbf{d f}$ & $\mathbf{x} \mathbf{2} / \mathbf{d f}$ & SRMR & GFI & IFI & CFI & RMSEA \\
\hline Structural & 104.38 & 79 & 1.320 & 0.055 & 0.940 & 0.980 & 0.980 & 0.042 \\
\hline
\end{tabular}

Table A in Appendix presents the empirical findings of the environmental attitude and ecolabeling mediation models with the significant structural paths and their standardized $\beta$ regression weights. Hypothesis 1 was rejected as collectivism has no direct significant impact on green buying intention as $(\beta=.09)$.

However, Hypotheses 4 and 7 were accepted as loyalty $(\beta=.23)$ and man-nature orientation as $(\beta=.13)$ have a direct impact on green buying intention. Whereas, Hypotheses 2,5 and 8 were also accepted as collectivism $(\beta=.41)$, loyalty $(\beta=.37)$ and man-nature orientation as $(\beta=.23)$ have direct significant impact on environmental attitude. Whereas, Hypotheses 3,6 and 9 were also accepted as collectivism $(\beta=.39)$, loyalty $(\beta=.28)$ and man-nature orientation as $(\beta=.40)$ have significant direct impact on eco-label. As expected, the results show that environmental attitude $(\beta=.38)$, and eco-label $(\beta=.41)$ were positively associated with green buying intention. Hence, 10, and 14 were also supported.

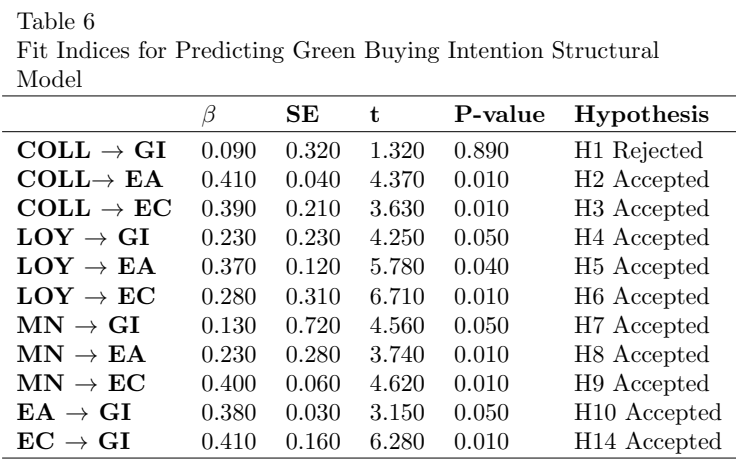

Next, to test the mediation Hypothesis, HLM hierarchal linear modeling bootstrapping steps guided by Preacher and Hayes (2008), as presented in the Table 7 and A in appendix, to test mediation were used the Hypothesis 8 posited that environmental attitude mediates the relationship between collectivism and green buying intention was accepted as mediating effect of the $(\beta=.16)$ was observed (see Table 7 ) and revealed full mediation. The model accounted for $18.8 \%$ of the variance predicting green intention based on 9 produced iterations (details of Bayesian information criterion test, log likelihood is also available in Table A which clearly validates the significance of estimated variance produced along with bootstrapping analysis). Similarly, Hypothesis 12 and 13 posited that environmental attitude mediates the relationship of the man-nature and loyalty with green buying intention 
were also supported as an indirect effect of the loyalty on green intention was significant $(\beta=.08)$ and model accounted for $23 \%$ of the variance to predict green intention based on 11 produced iterations. The indirect effect of the man-nature on green intention was significant $(\beta=.19)$. The model accounted for $19 \%$ of the variance in predicting green intention based on 9 produced iterations.

Figure 2

Path Analysis of Environmental Attitude Eco-labels mediation model in predicting Green Buying Intention

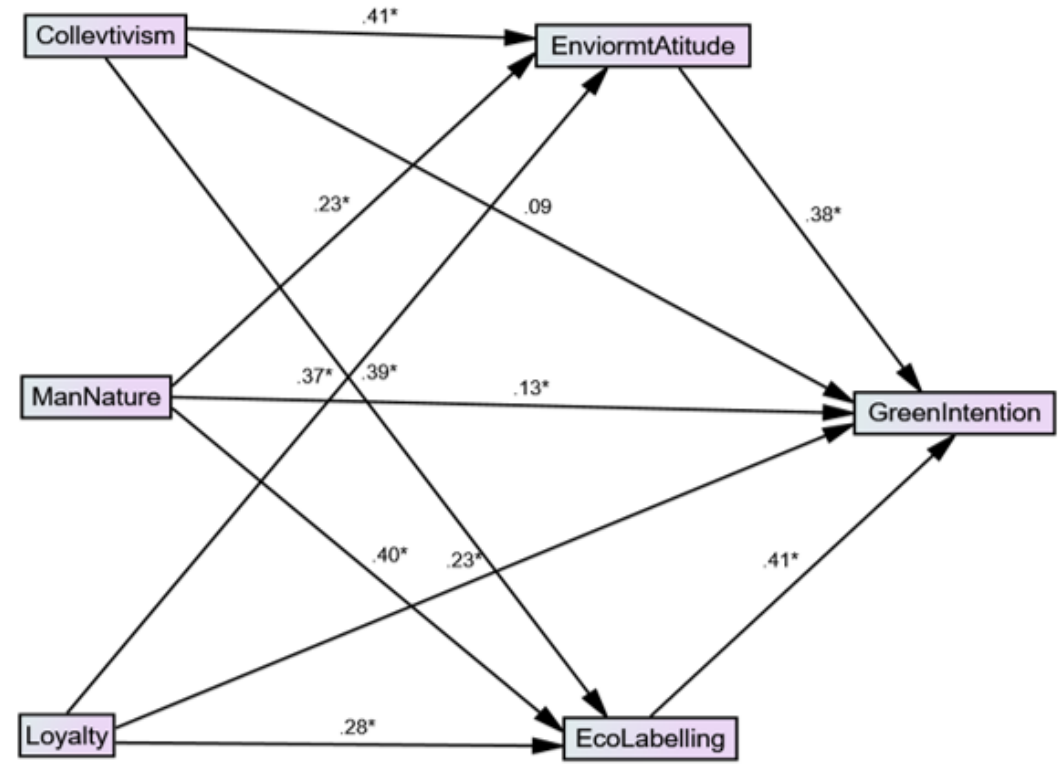

Hypothesis 15, 16 and 17 posited that eco-labels mediates the relationship of collectivism, loyalty and man-nature orientation with green buying intention were also supported as indirect effect of the collectivism on green intention was significant $(\beta=.12)$ and accounted $26 \%$ variance with 13 iterations which suggested full mediation as direct relationship was not significant. The indirect effect of the loyalty on green intention was significant $(\beta=.06)$. and accounted $13 \%$ variance with 18 iterations. The indirect effect of the man-nature on green intention was significant $(\beta=.13)$ and accounted $46 \%$ variance with 7 iterations.

Following the Dawson (2014) approach of analyzing the moderation of the categorical variable (i.e., gender), we have examined the effect of gender as moderating variable. This permits us to examine our assumption that the gender differences moderate the relationship between the eco-labeling and environmental attitude with green buying intention. We ran moderated multiple regression (MMR) analysis separately for the ecolabeling and environmental attitude interaction with the gender. For that reason, in first step reported gender by the sample was coded as a binary measure, where male $(\mathrm{X}=1)$ and female (X 
$=0)$. Hence, in our analysis, female aids as the reference (control group).

Table 7

Mediation Results

\begin{tabular}{lcccc}
\hline Hypothesis & Direct Effect $\beta$ & Indirect Effect $\beta$ & Result & Hypothesis \\
\hline $\mathbf{C O L L} \rightarrow \mathbf{E A} \rightarrow$ GI & $.090(\mathrm{~ns})$ & $.160^{*}(\mathrm{~s})$ & Full Mediation & H11 Accepted \\
$\mathbf{L O Y} \rightarrow \mathbf{E A} \rightarrow$ GI & $.230^{*}(\mathrm{~s})$ & $.080^{*}(\mathrm{~s})$ & Partial Mediation & H12 Accepted \\
$\mathbf{M N} \rightarrow \mathbf{E A} \rightarrow$ GI & $.130^{*}(\mathrm{~s})$ & $.190^{* *}(\mathrm{~s})$ & Partial Mediation & H13 Accepted \\
$\mathbf{C O L L} \rightarrow \mathbf{E L} \rightarrow$ GI & $.090(\mathrm{~ns})$ & $.120^{*}(\mathrm{~s})$ & Full Mediation & H15 Accepted \\
$\mathbf{M N} \rightarrow \mathbf{E L} \rightarrow$ GI & $.230^{*}(\mathrm{~s})$ & $.060^{*}(\mathrm{~s})$ & Partial Mediation & H16 Accepted \\
$\mathbf{L O Y} \rightarrow \mathbf{E L} \rightarrow$ GI & $.130^{*}(\mathrm{~s})$ & $.130^{* *}(\mathrm{~s})$ & Partial Mediation & H17 Accepted \\
\hline * Significant at $=\mathrm{p}<0.001{ }^{* *}$ significant at $=\mathrm{p}<0.050$ Not significant &
\end{tabular}

Table 8

Moderation Analysis with Gradients results

\begin{tabular}{lcccccccr}
\hline & \multicolumn{10}{c}{ Standard bootstrap results } \\
\hline Direct and Interaction Effects & $\beta$ & S. E & t-value & P-value & $\begin{array}{c}\text { Male } \\
\text { gradient }\end{array}$ & $\begin{array}{c}\text { Female } \\
\text { gradient }\end{array}$ & $\begin{array}{c}\text { Durbin Watsons } \\
\text { test }\end{array}$ & Hypothesis \\
\hline$(\mathrm{EA}) \rightarrow(\mathrm{GI})$ & 0.380 & 0.030 & 3.150 & 0.050 & - & - & - & \\
$(\mathrm{EL}) \rightarrow(\mathrm{GI})$ & 0.410 & 0.160 & 6.250 & 0.010 & - & - & - & \\
$($ Gender-X-EA $) \rightarrow$ GI & 0.190 & 0.080 & 9.020 & 0.040 & 0.400 & 0.450 & 1.870 & H18 Accepted \\
$($ GENDER-X-EL $\rightarrow$ GI & 0.260 & 0.040 & 11.21 & 0.010 & 0.380 & 0.520 & 2.130 & H19 Accepted \\
\hline
\end{tabular}

Second, the interactional term environmental attitude $\mathrm{X}$ gender (Male, $\mathrm{X}=1$ and female $=0$, dummy coded) and control variables (i.e., age) were added in the model. Our findings recommend that gender does serve as a moderator of the relationship between environmental attitude and green buying intention and significant interactional effect of environmental attitudes and gender was significant $(\mathrm{b}=0.19, \mathrm{p}=.04, \mathrm{t}=9.02)$ with acceptable value (1.87) of Durbin Watsons test and explained $49 \%$ of the total variance $\Delta R^{2} .07 \mathrm{p}<.05$. While, the direct effect of the environmental attitude on green intention for the males was (gradient $=.40$ ), and (gradient $=.45$ ) for the females, and both effects were significantly different which supported hypothesis 18 . This suggested that females are more inclined towards the green buying intention based on positive environmental attitudes.

Thirdly, a separate multiple regression model was used based on the interactional term ecolabel $\mathrm{X}$ gender (Male, $\mathrm{X}=1$ and female $=0$, dummy coded), our findings recommend that gender does serve as a moderator of the relationship between ecolabels and green buying intention $(\mathrm{b}=0.26, \mathrm{p}=.01, \mathrm{t}=11.21)$ with acceptable value $(2.13)$ of Durbin Watsons test and explained $42 \%$ of the total variance $\Delta R^{2}=.05 \mathrm{p}<.05$. Whereas, the direct effect of the ecolabels on green intention for the males was (gradient $=.38$ ), and (gradient $=.52$ ) for the females, and both effects were significantly different which supported hypothesis 19 . This suggested that females are more inclined towards the green buying intention based on positive perception of the ecolabels. Lastly, consistent with suggestion of Dawson (2014), we also examined our findings via slope test (see Figure 4 and 5), which supported that there is a difference between the slopes of female in both models. 


\section{Figure 4}

Moderation of gender in relationship of environmental attitudes and green intention

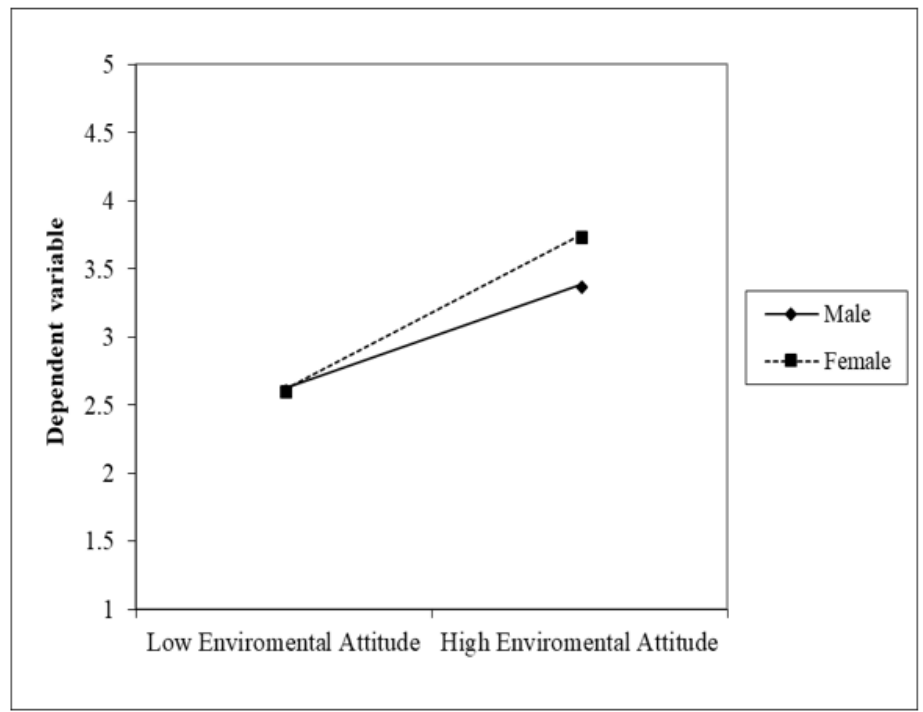

Figure 5

Moderation of gender in relationship of eco-labels and green intention

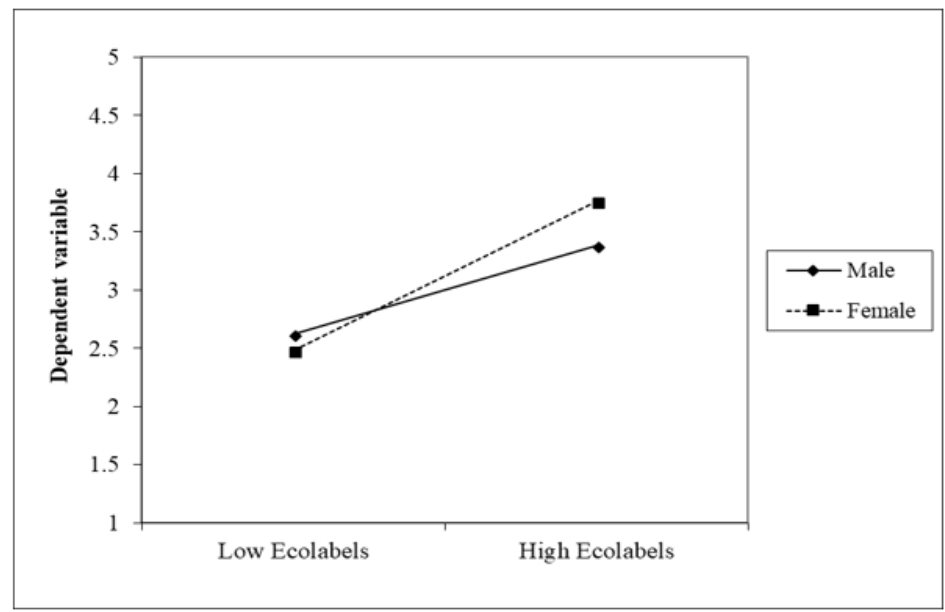

\section{Discussion and Conclusion}

The main purpose of this study was to empirically explore the impact of consumer personality on green buying intention. These personality characteristics are categorized into 
cultural factors and personal factors. Collectivism and man-nature orientation are the variables that comprised of cultural factors while on the other hand personal factors included loyalty proneness. This study also addressed environment by analyzing the environmental attitude and occurrence of eco-labels on products. The dependent variable of this study was green buying intention. Results of the data showed that measures are strong in terms of their composite reliability and indicator's reliability. The value of composite reliability ranges from 0.75 to 0.90 that shows that they are greater than the cut-off value of 0.7 (Gefen, Straub, \& Boudreau, 2000). The value of average variance extracted (AVE) of all the variables were greater than the cut-off value 0.5 (Hair, Sarstedt, Ringle, \& Mena, 2012). The value of Cronbach's Alpha is also more than the threshold value of 0.6 that shows that scales are stable and confirms a good internal consistency. Moss et al., (1998-as cited in - Sturmey, Newton, Cowley, Bouras, and Holt (2005) stated that the Cronbach's alpha of 0.6 is acceptable. Table 3 shows that the results of discriminant validity are also satisfactory depicting that square root of average variance extracted is greater than the correlations among latent variable square root of average variance (Agan, Acar, \& Borodin, 2013). As mentioned previously that basic purpose of this study is to hypothesize and test the model empirically that explains the impact of consumer personality on their green buying intention. The model described that it is integrated based upon individual's culture, attitudes and marketing tools that focused on the consumer behavior disciplines.

Though our results concerning collectivism impact green buying intention does not support our hypothesis, the results of the study shed lights on the practical and contextual way researched variables play a role on green buying intention and that shows the ultimate behavior. The results depict that environmental attitude acts as the variable that further leads to green buying intention confirming findings from previous studies by Rahbar and Abdul Wahid (2011); Chen and Chai (2010) . This attitude is formed or developed spontaneously or subconsciously by consumers where they feel a sense of responsibility towards the environment to help save it and to prevent it from further deterioration. Albeit the direct influence of collectivism on intention remained not significant nevertheless these results have interesting implications in context of Pakistan. However, is is steady with the past studies conducted in other regions of Asia. For instance, Ghazali et al. (2017) found that there is no significant influence of the collectivism on Malaysian customers' preferences. According to de Mooij (2017) Hofstede dimensions are designed to measure the individual level preferences and may reveal difference results from relevant dimension's national index. Similarly, (Brewer \& Venaik, 2012) noted that these discrepancies in cultural studies are since results represents a specific segment of the country which may vary from the national level index.

In addition, consistent with the Hofstede and TPB model, collectivism as a cultural factor serves as antecedent of the several attitudes such as environmental attitude. Hofstede (2001) noted that individuals learn several attitudes through culture which may in turn influence their behavioral pattern. Similar to the Hofstede view results suggest that collectivism-intention relationship is routed through the environmental attitude (see Table 7). The findings are also in accordance with the collectivist Pakistani cultural context and uphold the collectivist beliefs (Raza, Abu Bakar, \& Mohamad, 2019). In other words, Pakistani people uphold more collectivist beliefs which have influenced their attitudes and resulting 
in improved intention to buy green products. As people in collectivist culture prefer collective goals than individual goals and thus try to make decisions that can benefit society collectively (Kanchanapibul et al., 2014). In this scenario, TPB notion that beliefs serve as the antecedent of the attitude has been validated by our results. Pakistanis traditionally hold collectivist beliefs (such as collectivism) which influence the environmental attitude. In a collectivist country such as Pakistan these patterns can be observed more frequently wherein individuals learn attitudes through culture. The results of present study established the mediating effect of environmental attitudes and suggests that green products may support to connect more collective beliefs.

Also, there is a relationship between eco-labels and green buying intention which is also found consistent with the previous studies. Previous studies claimed that eco-labels to be one of the drivers of green buying intention by Rahbar and Abdul Wahid (2011). It is quite evident from this research study that awareness and trust on the eco-labels influence a lot on green buying intention of a consumer. Research posits that presence of eco-labels increases consumer's familiarity and imparts a positive perception of green products over the conventional ones. As far as cultural influence is concerned, there is a positive relationship between man-nature orientation and green buying intention which is also consistent with the previous studies (Rehman \& Dost, 2013; Mun, 2009; Chan, 2001) also proved a positive relation of man-nature orientation with environmental attitude of consumer on ecologically friendly buying behavior. This is desirable in terms of psychology as thoughts (the reasoning function) and feelings (emotional function) are influenced by an attitude which eventually affects consumer behavior including buying intention.

Upon testing it was surprisingly found that collectivism doesn't show a significant relationship between green buying intention. According to Rucker, Preacher, Tormala, and Petty (2011) if there is no significant relationship between variables then there exist an intervening variable mediating their relationship which has been strongly proved by mediating variables of the study. This also sheds light to analyze the behavior of collectivism in future studies.

Loyalty proneness also showed a positive relation with green buying intention. This result also supports the findings of previous researchers. Green practices and green buying intentions are the robust prognosticators of consumer's attachment to the store emotionally. Green buying intention ultimately acts as a predictor of store attachment and consumer's thus gets inclined to buy the green product. Consumers with high green consciousness also get attached with stores and show their intent to exhibit green buying intention and purchase the green product which is also inconsistent with the studies of Jang et al. (2015); Yusof, Musa, and Rahman (2012). The impact of male gender as moderator showing to have a positive effect on green buying intention which is also consistent to previous studies by Diamantopoulos et al. (2003) likewise age plays a positive impact on green buying intention showing that age 36-45 are more prone to show favorable ecological behavior as they are ones with more of the knowledge of eco-labels. Hence, we dedicate present revealing findings to the 18th European Round table for Sustainable Consumption and Production (18th ERSCP 2017) orienting organizations business life cycles towards sustainability by the adoption of required drivers and innovative concepts. 


\section{Theoretical and Practical Contribution}

By understanding and conceptualizing the fact that green product influences choices and decisions of consumers, it can help marketers to identify that how they can develop their marketing communications regarding environment-related services and products in developing societies. This perspective can certainly provide insights that how advancements can be made in a country like Pakistan regarding green consumption .

Consumers must be anxious about the implications related to business perspective in Pakistan, the results of this study complement this notion of the author. With the adoption of green consumption, firms can use opportunities regarding green products in Pakistani market, can enhance the image of product in corporations, to follow all the ecological trends, they can take a competitive advantage and most importantly they can raise the buying intention of consumers (Rizwan et al., 2013). Further, marketers should focus to incorporate collectivistic beliefs in their promotional campaigns so that purchase intention for green products can be increased amongst these groups. To exemplify ecolabeled messages can make consumers more conscious about collective benefits of the green products. These sorts of collective benefits can trigger a positive cognitive process among a collective society like Pakistan and can lead towards a favorable evaluation of green product.

Research companies, marketing managers, and academics have shed light on the factors which help consumers and guide them to go for green products and show green buying intention. This creates a new set of opportunities for marketers to establish a new category of green products in order to maximize and increase their firm's profits by mounting up their share in the market. This also creates a bigger challenge for marketers to devise up marketing strategies that not only attract consumers rather safeguard the optimal sales. Though green marketing is an important issue that is getting the point of discussion nowadays still a lot of efforts are needed by marketers to shape the green purchase intention of Pakistani consumers. Marketers should utilize the benefits of incorporating green practices and thus increase their competitive advantage as green buying intention acts as the voice of consumer's heart to purchase those products that are ecologically friendly (Rizwan et al., 2013). Since in developing countries like Pakistan the concept of green buying is at developmental stages. 


\section{References}

Agan, Y., Acar, M. F., \& Borodin, A. (2013). Drivers of environmental processes and their impact on performance: A study of Turkish SMEs. Journal of Cleaner Production, $51,23-33$.

Ajzen, I. (1985). From intentions to actions: A theory of planned behavior. In Action control (pp. 11-39). Springer.

Ajzen, I. (1991). The theory of planned behavior. Organizational Behavior and Human Decision Processes, 50(2), 179-211.

Ali, A., Khan, A. A., Ahmed, I., \& Shahzad, W. (2011). Determinants of Pakistani consumers' green purchase behavior: Some insights from a developing country. International Journal of Business and Social Science, 2(3), 217-226.

Aman, A. L., Harun, A., \& Hussein, Z. (2012). The influence of environmental knowledge and concern on green purchase intention the role of attitude as a mediating variable. British Journal of Arts and Social Sciences, 7(2), 145-167.

Arısal, İ., \& Atalar, T. (2016). The exploring relationships between environmental concern, collectivism and ecological purchase intention. Procedia-Social and Behavioral Sciences, 235, 514-521.

Arto, I., \& Dietzenbacher, E. (2014). Drivers of the growth in global greenhouse gas emissions. Environmental Science \&5 Technology, 48(10), 5388-5394.

Bang, H.-K., Ellinger, A. E., Hadjimarcou, J., \& Traichal, P. A. (2000). Consumer concern, knowledge, belief, and attitude toward renewable energy: An application of the reasoned action theory. Psychology \& Marketing, 17(6), 449-468.

Barbaro, N., Pickett, S. M., \& Parkhill, M. R. (2015). Environmental attitudes mediate the link between need for cognition and pro-environmental goal choice. Personality and Individual Differences, 75, 220-223.

Belanche, D., Flavián, C., \& Pérez-Rueda, A. (2017). Understanding interactive online advertising: Congruence and product involvement in highly and lowly arousing, skippable video ads. Journal of Interactive Marketing, 37, 75-88.

Brécard, D. (2014). Consumer confusion over the profusion of eco-labels: Lessons from a double differentiation model. Resource and Energy Economics, 37, 64-84.

Brewer, P., \& Venaik, S. (2012). On the misuse of national culture dimensions. International Marketing Review, 29(6), 673-683.

Cai, Z., Xie, Y., \& Aguilar, F. X. (2017). Eco-label credibility and retailer effects on green product purchasing intentions. Forest Policy and Economics, 80, 200-208.

Chairy, C. (2012). Spirituality, self-transcendence, and green purchase intention in college students. Journal of Education, Society and Behavioural Science, 57, 243-246.

Chan, R. Y. (2001). Determinants of Chinese consumers' green purchase behavior. Psychology \& Marketing, 18(4), 389-413.

Chekima, B., Wafa, S. A. W. S. K., Igau, O. A., Chekima, S., \& Sondoh Jr, S. L. (2016). Examining green consumerism motivational drivers: Does premium price and demographics matter to green purchasing? Journal of Cleaner Production, 112, 34363450 . 
Chen, T. B., \& Chai, L. T. (2010). Attitude towards the environment and green products: consumers' perspective. Management Science and Engineering, 4(2), 27-39.

Churchill Jr, G. A. (1979). A paradigm for developing better measures of marketing constructs. Journal of Marketing Research, 16(1), 64-73.

Clemenz, G. (2010). Eco-labeling and horizontal product differentiation. Environmental and Resource Economics, 45(4), 481-497.

Crumpei, I., Boncu, S., \& Crumpei, G. (2014). Environmental attitudes and ecological moral reasoning in Romanian students. Procedia-Social and Behavioral Sciences, $114,461-465$.

Dawson, J. F. (2014). Moderation in management research: What, why, when, and how. Journal of Business and Psychology, 29(1), 1-19.

de Mooij, M. (2017). Comparing dimensions of national culture for secondary analysis of consumer behavior data of different countries. International Marketing Review, $34(3), 444-456$.

Diamantopoulos, A., Schlegelmilch, B. B., Sinkovics, R. R., \& Bohlen, G. M. (2003). Can socio-demographics still play a role in profiling green consumers? A review of the evidence and an empirical investigation. Journal of Business Research, 56(6), $465-480$.

Escalas, J. E., \& Bettman, J. R. (2005). Self-construal, reference groups, and brand meaning. Journal of Consumer Research, 32(3), 378-389.

Frank, B., Enkawa, T., \& Schvaneveldt, S. J. (2015). The role of individualism vs. collectivism in the formation of repurchase intent: A cross-industry comparison of the effects of cultural and personal values. Journal of Economic Psychology, 51, 261-278.

Franzen, A., \& Mader, S. (2016). Predictors of national CO 2 emissions: Do international commitments matter? Climatic Change, 139(3-4), 491-502.

Frost, D., Goode, S., \& Hart, D. (2010). Individualist and collectivist factors affecting online repurchase intentions. Internet Research, 20(1), 6-28.

Gadenne, D., Sharma, B., Kerr, D., \& Smith, T. (2011). The influence of consumers' environmental beliefs and attitudes on energy saving behaviours. Energy Policy, $39(12), 7684-7694$.

Gallagher, K. S., \& Muehlegger, E. (2011). Giving green to get green? Incentives and consumer adoption of hybrid vehicle technology. Journal of Environmental Economics and Management, 61 (1), 1-15.

Gefen, D., Straub, D., \& Boudreau, M.-C. (2000). Structural equation modeling and regression: Guidelines for research practice. Communications of the Association for Information Systems, 4(1). doi: 10.17705/1CAIS.00407

Ghazali, I., Abdul-Rashid, S. H., Dawal, S. Z. M., Aoyama, H., Tontowi, A. E., \& Sakundarini, N. (2017). Cultural influences on choosing green products: An empirical study in Malaysia. Sustainable Development, 25 (6), 655-670.

Giridhar, T. (1998). Eco-labelling: A comparative analysis. Chemical Business, 12(7), 95-98.

Hair, J. F., Sarstedt, M., Ringle, C. M., \& Mena, J. A. (2012). An assessment of the use of partial least squares structural equation modeling in marketing research. Journal of the Academy of Marketing Science, 40(3), 414-433. 
Hair Jr, J. F., Babin, B. J., \& Krey, N. (2017). Covariance-based structural equation modeling in the journal of advertising: Review and recommendations. Journal of Advertising, 46(1), 163-177.

Hofstede, G. (1997). Cultures and orgs: Software of the mind. NY: McGraw-Hill.

Hofstede, G. (2001). Culture's consequences: Comparing values, behaviors, institutions and organizations across nations. US: Sage publications.

Hu, L.-t., \& Bentler, P. M. (1999). Cutoff criteria for fit indexes in covariance structure analysis: Conventional criteria versus new alternatives. Structural Equation Modeling: A Multidisciplinary Journal, 6(1), 1-55.

Huang, Y.-C., Yang, M., \& Wang, Y.-C. (2014). Effects of green brand on green purchase intention. Marketing Intelligence \& Planning, 32(3), 250-268.

Husted, B. W., \& Allen, D. B. (2008). Toward a model of cross-cultural business ethics: The impact of individualism and collectivism on the ethical decision-making process. Journal of Business Ethics, 82(2), 293-305.

Husted, B. W., Russo, M. V., Meza, C. E. B., \& Tilleman, S. G. (2014). An exploratory study of environmental attitudes and the willingness to pay for environmental certification in Mexico. Journal of Business Research, 67(5), 891-899.

Jaiswal, N. (2012). Green products: Availability, awareness and preference of use by the families. Indian Journal of Environmental Education, 12, 21-25.

Jang, Y. J., Kim, W. G., \& Lee, H. Y. (2015). Coffee shop consumers' emotional attachment and loyalty to green stores: The moderating role of green consciousness. International Journal of Hospitality Management, 44, 146-156.

Junaedi, M. S. (2006). Pengembangan model perilaku konsumen berwawasan lingkungan di Indonesia: Studi perbandingan kota metropolitan dan non metropolitan. Jurnal Ekonomi dan Bisnis Indonesia, $21(4), 34-45$.

Kalamas, M., Cleveland, M., \& Laroche, M. (2014). Pro-environmental behaviors for thee but not for me: Green giants, green gods, and external environmental locus of control. Journal of Business Research, 67(2), 12-22.

Kanchanapibul, M., Lacka, E., Wang, X., \& Chan, H. K. (2014). An empirical investigation of green purchase behaviour among the young generation. Journal of Cleaner Production, 66, 528-536.

Keller, K. L. (2016). Unlocking the power of integrated marketing communications: How integrated is your IMC program? Journal of Advertising, 45(3), 286-301.

Kim, Y. (2011). Understanding green purchase: The influence of collectivism, personal values and environmental attitudes, and the moderating effect of perceived consumer effectiveness. Seoul Journal of Business, 17(1), 65-92.

Kim, Y., \& Choi, S. M. (2005). Antecedents of green purchase behavior: An examination of collectivism, environmental concern, and PCE. ACR North American Advances, 592-599.

Kluckhohn, F. R., \& Strodtbeck, F. L. (1961). Variations in value orientations. Oxford, England: Row, Peterson.

Kumar, N., Scheer, L. K., \& Steenkamp, J.-B. E. (1995). The effects of perceived interdependence on dealer attitudes. Journal of Marketing Research, 32(3), 348-356. 
Laroche, M., Kalamas, M., \& Cleveland, M. (2005). "I" versus "we" how individualists and collectivists use information sources to formulate their service expectations. International Marketing Review, 22(3), 279-308.

Lee, K. (2008). Opportunities for green marketing: Young consumers. Marketing Intelligence \& Planning, 26(6), 573-586.

Lu, L.-C., Chang, H.-H., \& Chang, A. (2015). Consumer personality and green buying intention: The mediate role of consumer ethical beliefs. Journal of Business Ethics, $127(1), 205-219$.

Matthes, J., Wonneberger, A., \& Schmuck, D. (2014). Consumers' green involvement and the persuasive effects of emotional versus functional ads. Journal of Business Research, 67(9), 1885-1893.

Memon, M., Ting, H., Ramayah, T., Chuah, F., \& Cheah, J. (2017). A review of the methodological misconceptions and guidelines related to the application of structural equation modeling: A Malaysian scenario. Journal of Applied Structural Equation Modeling, 1(1), 1-13.

Milfont, T. L., \& Duckitt, J. (2010). The environmental attitudes inventory: A valid and reliable measure to assess the structure of environmental attitudes. Journal of Environmental Psychology, 30(1), 80-94.

Minoli, D. M., Goode, M. M., \& Smith, M. T. (2015). Are eco labels profitably employed in sustainable tourism? A case study on Audubon Certified Golf Resorts. Tourism Management Perspectives, 16, 207-216.

Mun, C. C. (2009). A study on consumers 'green purchasing intention'. Unpublished Thesis Master of Business Administration. Universiti Utara Malaysia.

Noordin, F., \& Jusoff, K. (2010). Individualism-collectivism and job satisfaction between Malaysia and Australia. International Journal of Educational Management, 24(2), 159-174.

Oliver, J. D., \& Rosen, D. E. (2010). Applying the environmental propensity framework: A segmented approach to hybrid electric vehicle marketing strategies. Journal of Marketing Theory and Practice, 18(4), 377-393.

Pickett-Baker, J., \& Ozaki, R. (2008). Pro-environmental products: Marketing influence on consumer purchase decision. Journal of Consumer Marketing, 25(5), 281-293.

Prakash, G., \& Pathak, P. (2017). Intention to buy eco-friendly packaged products among young consumers of India: A study on developing nation. Journal of Cleaner Production, 141, 385-393.

Preacher, K. J., \& Hayes, A. F. (2008). Asymptotic and resampling strategies for assessing and comparing indirect effects in multiple mediator models. Behavior Research Methods, 40(3), 879-891.

Proto, M., Malandrino, O., \& Supino, S. (2007). Eco-labels: A sustainability performance in benchmarking? Management of Environmental Quality: An International Journal, 18(6), 669-683.

Rahbar, E., \& Abdul Wahid, N. (2011). Investigation of green marketing tools' effect on consumers' purchase behavior. Business Strategy Series, 12(2), 73-83.

Rajagopal, R. (2011). Consumer culture and purchase intentions toward fashion apparel in Mexico. Database Marketing \& Customer Strategy Management, 18(4), 286-307. 
Rashid, N. (2009). Awareness of eco-label in Malaysia's green marketing initiative. International Journal of Business and Management, 4(8), 132-141.

Raza, S. H., Abu Bakar, H., \& Mohamad, B. (2019). The effects of advertising appeals on consumers' behavioural intention towards global brands: The mediating role of attitude and the moderating role of uncertainty avoidance. Journal of Islamic Marketing.

Raza, S. H., Bakar, H. A., \& Mohamad, B. (2018). Advertising appeals and Malaysian culture norms. Journal of Asian Pacific Communication, 28(1), 61-82.

Raza, S. H., Hasnain, A., \& Khan, S. W. (2018). Cross-cultural evaluation of the mediation of attitudes in relationship of cultural values and behavioral reactions toward web based advertising. South Asian Journal of Management Sciences, 12(1), 1-24.

Rehman, Z.-u., \& Dost, M. B. (2013). Conceptualizing green purchase intention in emerging markets: An empirical analysis on Pakistan. In The 2013 WEI International Academic Conference Proceedings (p. 99-120).

Ritter, A. M., Borchardt, M., Vaccaro, G. L., Pereira, G. M., \& Almeida, F. (2015). Motivations for promoting the consumption of green products in an emerging country: Exploring attitudes of Brazilian consumers. Journal of Cleaner Production, 106, $507-520$.

Rizwan, M., Aslam, A., ur Rahman, M., Ahmad, N., Sarwar, U., Asghar, T., et al. (2013). Impact of green marketing on purchase intention: An empirical study from Pakistan. Asian Journal of Empirical Research, 3(2), 87-100.

Rucker, D. D., Preacher, K. J., Tormala, Z. L., \& Petty, R. E. (2011). Mediation analysis in social psychology: Current practices and new recommendations. Social and Personality Psychology Compass, 5(6), 359-371.

Saad, G., Cleveland, M., \& Ho, L. (2015). Individualism-collectivism and the quantity versus quality dimensions of individual and group creative performance. Journal of Business Research, 68(3), 578-586.

Sangroya, D., \& Nayak, J. K. (2017). Factors influencing buying behaviour of green energy consumer. Journal of Cleaner Production, 151, 393-405.

Steenhaut, S., \& Van Kenhove, P. (2005). Relationship commitment and ethical consumer behavior in a retail setting: The case of receiving too much change at the checkout. Journal of Business Ethics, 56(4), 335-353.

Tanner, C., \& Wölfing Kast, S. (2003). Promoting sustainable consumption: Determinants of green purchases by Swiss consumers. Psychology \& Marketing, 20(10), 883-902.

Triandis, H. C., \& Gelfand, M. J. (1998). Converging measurement of horizontal and vertical individualism and collectivism. Journal of Personality and Social Psychology, $74(1), 118$.

Tsay, Y.-Y. (2009). The impacts of economic crisis on green consumption in Taiwan. In Picmet'09-2009 Portland International Conference on Management of Engineering E Technology (pp. 2367-2374).

Turkyilmaz, C. A., Uslu, A., \& Durmus, B. (2015). Antecedents and outcomes of consumers' inward and outward environmental attitudes: Evidence from Turkey. Procedia-Social and Behavioral Sciences, 175, 90-97.

VanVoorhis, C. W., \& Morgan, B. L. (2007). Understanding power and rules of thumb for 
determining sample sizes. Tutorials in Quantitative Methods for Psychology, 3(2), $43-50$.

Yazdanpanah, M., \& Forouzani, M. (2015). Application of the theory of planned behaviour to predict iranian students' intention to purchase organic food. Journal of Cleaner Production, 107, 342-352.

Yoo, M., \& Bai, B. (2013). Customer loyalty marketing research: A comparative approach between hospitality and business journals. International Journal of Hospitality Management, 33, 166-177.

Yusof, J. M., Musa, R., \& Rahman, S. A. (2012). The effects of green image of retailers on shopping value and store loyalty. Procedia-social and Behavioral Sciences, 50, 710-721. 